BBA 55090

METABOLISM OF PLASMALOGEN

III. RELATIVE REACTIVITIES OF ACYL AND ALKENYL DERIVATIVES OF GLYCEROL-3-PHOSPHORYLCHOLINE

WILLIAM E. M. LANDS AND PRISCILLA HART

Department of Biological Chemistry.

The University of Michigan, Ann Arbor, Mich. (U.S.A.)

(Received July $7^{\text {th }}$, 1964)

SUMMARY

(I) The alkenyl ether derivatives of phospholipids (plasmalogens) react at slower rates than the acyl analogs in several enzyme-catalyzed reactions.

(2) Alkenylglycerol-3-phosphorylcholine is essentially inert as a substrate for acyl-CoA : phospholipid acyltransferase. This result suggests that in vivo the 2-acyl substituent may be present before the alkenyl ether group is formed in the molecule.

(3) Alkenyl acylglycerol 3-phosphorylcholine is essentially inert as a substrate for cabbage phospholipase $\mathrm{D}$ (EC 3.I.4.4.). This lack of reactivity allows a convenient separation of alkenyl acylglycerol 3-phosphorylcholine from its diacyl analog in naturally occurring mixtures.

INTRODUCTION

The close similarities in the structures of plasmalogens (I) and diacyl phosphatides (II) suggest that these compounds may be metabolized by similar pathways.<smiles>[R]C=COCC(C[R]([O-])([O-])O)C([R])=O</smiles><smiles>[R]C(=O)CC(CC(C)OC([R])=O)[P+]([O-])([O-])O</smiles>

This suggestion is supported by the results of SchmidT et al. ${ }^{1}$ who showed that both plasmalogen and diester phosphatides contained as $P$ with equal specific activity at various times after radioactive inorganic phosphate was injected into rats. Further.

Abbreviations: GPC, glycerol 3-phosphorylcholine; GPE, glycerol 3-phosphorylethanolamine.

Biochim. Biophys. Acta, 98 (1965) 532-538 
more, KIYASU AND KENNEDY 2 showed that the reaction catalyzed by CDPcholine diglyceride cholinephosphotransferase (EC 2.7.8.2) occurs at comparable rates with alkenyl acylglycerol and diacylglycerol. Although KIYASU AND KENNEDY got some suggestive evidence that separate enzymes may be involved, their conclusion was that, if different, the enzymes must be strikingly similar. Thus, the metabolic turnover of the phosphorylcholine portion of the glycerolipids appeared to be unaffected by the presence of the alkenyl group.

The above experiments can be cited to emphasize the similarities in metabolism of the alkenyl and acyl derivatives, but HARTREE ${ }^{8}$ has reported evidence for a preferential reactivity (hydrolysis and oxidation) of the acyl group of alkenyl acyl-GPC in washed, "resting" preparations of ram spermatozoa. In contrast to this, evidence for a low level of plasmalogen reactivity with phospholipase A (EC 3.I.I.4) was given by MARINETTI et al. $\star$. These workers also interpreted earlier results of RAPPORT AND FRANZL $^{B}$ as indicating a slower rate of venom-catalyzed hydrolysis for alkenyl acylGPC than diacyl-GPC. This low reactivity was later confirmed and utilized by GoTTFRIED AND RAPPORT in preparing pure alkenyl acyl-GPC.

Similarly the reverse type of reaction, acylation of alkenyl-GPC to form alkenyl acyl-GPC, does not take place under conditions whereby acyl-GPC is readily acylated ${ }^{7}$. Further work in this laboratory has shown that in a variety of reactions the alkenyl ether derivatives react at slower rates than the acyl analogs. This lack of reactivity is particularly marked in the reaction catalyzed by cabbage phospholipase D (EC 3.I.4.4) so that pure alkenyl acyl-GPC can easily be prepared with high yield.

\section{MATERIAIS AND METHODS}

The lecithin and cephalin fractions of beef heart phosphatides were prepared by silicic acid chromatography and the alkenyl-GPC was prepared by alkaline hydrolysis as described earlier ${ }^{B}$. Acyl-GPC was prepared by venom catalyzed hydrolysis of purified egg lecithin' and the ether-insoluble product was purified by silicic acid chromatography. The lyophilized venom was obtained from the Ross Allen's Reptile Institute and cabbage phospholipase D from the California Corporation for Biochemical Research. The microsome preparation was the material sedimenting between 25000-I00000 $\times g$ from a $0.25 \mathrm{M}$ sucrose homogenate of rat liver.

The above materials were analyzed, as were the products of the phospholipasecatalyzed reaction, by methods described earlicr ${ }^{10}$.

\section{Acyltransferase reaction}

The I-ml reaction mixture contained $40 \mathrm{~m} \mu$ moles of $\left[{ }^{14} \mathrm{C}\right]$ oleyl-CoA(64 counts $/ \mathrm{min}$ per $\mathrm{m} \mu \mathrm{mole}$ ), $0.05 \mathrm{ml}$ of a freeze-thawed microsomal fraction (30 $\mathrm{mg}$ protein $/ \mathrm{ml}$ ), and varied amounts of acyl-GPC or alkenyl-GPC as indicated in Table I. After incubating for $7 \mathrm{~min}$ at $37^{\circ}$ the reaction was stopped with $20 \mathrm{ml}$ of $33 \%$ methanol in chloroform, and the lipids were isolated by silicic acid chromatography ${ }^{11}$. The data represent the m $\mu$ moles of ${ }^{14} \mathrm{C}$ joleic acid above the control value incorporated into the lecithin fraction.

Additional data were obtained with the direct spectrophotometric assay ${ }^{12}$ of acyltransferase using alkenyl, alkyl, and acyl-derivatives of GPC. 


\section{Phospholipase D reaction}

A sample of beef heart lecithin containing approximately $40 \%$ acyl alkenylGPC was dried in a round-bottom flask and then suspended in $20 \mathrm{ml}$ of imidazole chloride buffer (0.2 M, pH 7.0), $2 \mathrm{ml}$ of $\mathrm{I} \mathrm{M} \mathrm{CaCl}_{2}$ and $30 \mathrm{ml}$ of water. A solution of $20 \mathrm{mg}$ of cabbage phospholipase $\mathrm{D}(0.75$ units $/ \mathrm{mg})$ in $5 \mathrm{ml}$ of water was added, and after the lipid was well emulsified $50 \mathrm{ml}$ of ether were added. The reaction was allowed to proceed overnight or longer.

As much of the ether as possible was evaporated on the rotary evaporator, and then $2.5 \mathrm{ml}$ of I M sodium EDTA ( $\mathrm{pH} 8.0$ ) were added. This aqueous mixture was then extracted twice with $75-100 \mathrm{ml}$ of $33 \%$ methanol in chloroform. The combined organic extracts were then washed with water. At this point a bad emulsion usually resulted. Various techniques, such as centrifugation and adding more methanol, were employed until the emulsion was broken. The final cloudy organic layer was cleared with methanol and evaporated to dryness. The lipids were then taken up in absolute ethanol, and the $\mathrm{pH}$ was carefully adjusted to 7.5 with small additions of $2 \mathrm{~N} \mathrm{NaOH}$ saturated with $\mathrm{NaCl}$. In some experiments, excessive alkali was apparently added since a considerable amount of ether-insoluble alkenyl-GPC was formed. The amorphous precipitate of sodium diacylglycerol 3-phosphate generally contained considerable amounts of occluded alkenyl acyl-GPC that could be easily removed by reprecipitating the material from fresh ethanol. The ethanol-insoluble precipitate of sodium diacylglycerol 3-phosphate was removed by centrifugation, washed with ethanol, and dissolved in chloroform. In some experiments the ethanolic supernatant and washes were combined and passed through a Io-g silicic acid column. The column was eluted with ethanol, 10\% methanol in ethanol and $75 \%$ methanol in ethanol, and the fractions ( $75 \%$ methanol in ethanol) containing alkenyl acyl-GPC were combined and evaporated. This procedure removed small amounts of diacylglycerol phosphate and other impurities, but did not consistently improve the analytical values of the product.

\section{RESULTS}

Alkenyl-GPC was shown to be inert as an acceptor for oleate transfer (Table I). The results with mixtures of acyl- and alkenyl-GPC indicate that this negative result

\section{TABLE I}

INCORPORATION OF OLEATE INTO CHOLINE-

CONTAINING PHOSPHOLIPIDS

\begin{tabular}{|c|c|c|}
\hline $\begin{array}{l}\text { Alkenyl-GPC } \\
\text { (Amoles) }\end{array}$ & $\begin{array}{l}\text { Acyl-GPC } \\
\text { (Amoles) }\end{array}$ & $\begin{array}{l}\text { Oleyl transfer } \\
\text { (mumoles } / 7 \text { min) }\end{array}$ \\
\hline $0.5^{\circ}$ & 0 & 0.6 \\
\hline 0.40 & 0.10 & I. 7 \\
\hline 0.25 & 0.25 & 4.2 \\
\hline 0.10 & $0.4^{\circ}$ & 5.1 \\
\hline 0 & $0.5^{\circ}$ & 5.8 \\
\hline
\end{tabular}

is probably due to enzymatic specificity rather than any inhibitor that might be in the alkenyl-GPC. In this case the radioactive choline phosphatide fraction was purified by silicic acid chromotography, and the extent of reaction was calculated as $m \mu$ moles of oleate incorporated. The "continuous" spectrophotometric assay provided values 
of released CoASH every $20 \mathrm{sec}$. The rates of reaction in Table II compare favorably with those in Table I to support the conclusion that the alkenyl derivative is not appreciably acylated under these conditions.

\section{TABLE II}

COMPARISON OF ACYL-, ALKENYL- AND ALKYL-GPC AS ACCEPTORS IN THE ACYLTRANSFERASE REACTION

The I-ml reaction mixture contained $80 \mathrm{~m} \mu$ moles of oleyl-CoA, $50 \mathrm{~m} \mu \mathrm{moles}$ of acyl-GPC or other substrates as indicated, $50 \mu$ of a microsomal preparation, ro $\mu$ moles of bisdithionitrobenzoate and $50 \mu$ moles of Tris-chloride buffer (pH 7.4).

\begin{tabular}{|c|c|}
\hline $\begin{array}{l}\text { GPC-derivative added } \\
\text { (mumoles) }\end{array}$ & mumoles/ml/min \\
\hline 50 acyl- & I.05 \\
\hline 50 alkenyl- & 0 \\
\hline 5o alkyl- & 0 \\
\hline 50 acyl- & 0.96 \\
\hline 5o acyl- +50 alkenyl- & 0.68 \\
\hline 50 acyl- - 50 alkyl- & 0.88 \\
\hline
\end{tabular}

The analytical values given in Table III illustrate the reason why the preparation of alkenyl acyl-GPC was repeated so many times. The ester values are higher than expected, and the alkenyl ether values are lower than expected even though the sum of ester and alkenyl was equal to twice the phosphorus value, as would be expected. The ratio of alkenyl ether to phosphorus in the majority of preparations was 0.87 . A check of the analytical procedures did not provide an explanation for this discrepancy. It should be noted that GoTTFRIED AND RAPPORT obtained a value of 0.92 to 0.94 in their best preparation of alkenyl acyl-GPC. Those authors stated that such deviations from the theoretical value are consistent with results obtained with model com-

TABLE III

PURIPICATION OF ALKENYL ACYL-GPC FROM NATURALLY OCCURRING MIXTURES

\begin{tabular}{|c|c|c|c|c|c|c|c|}
\hline \multirow{2}{*}{$\begin{array}{l}\text { Expt. } \\
\text { No. }\end{array}$} & \multirow{2}{*}{$\begin{array}{l}\text { Initial } \\
\text { material } \\
\text { phos. } \\
\text { ( } \mu \text { moles) }\end{array}$} & \multirow{2}{*}{ 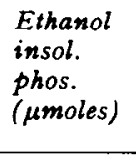 } & \multicolumn{5}{|c|}{ Ethanol soluble } \\
\hline & & & 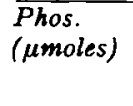 & $\begin{array}{l}\text { Alkenyl } \\
\text { (umoles) }\end{array}$ & $\begin{array}{l}\text { Ester } \\
\text { ( } \mu \text { moles) }\end{array}$ & $\begin{array}{l}\text { Ester + } \\
\text { alkenyl } \\
\text { phos. }\end{array}$ & $\frac{\text { Alkenyl }}{\text { phos. }}$ \\
\hline 19 & 1055 & 522 & 395 & $3^{88}$ & 400 & 2.00 & 0.98 \\
\hline 20 & 1268 & 652 & 605 & 490 & 700 & 1.97 & $0.8 \mathrm{I}$ \\
\hline 23 & I 268 & 443 & 548 & 467 & 655 & 2.05 & 0.86 \\
\hline
\end{tabular}

pounds. Similarly, ANSELl AND SPANNER ${ }^{18}$ give a value of 0.87 for their preparation of alkenyl acyl-GPE from brain which was "the purest native ethanolamine plasmalogen so far obtained." Using hydrolytic techniques with acid, alkali and refluxing HI, we could not demonstrate that the low ratio in our experiments was due to either sphingomyelin contamination ${ }^{*}$ or alkylglycerol derivatives ${ }^{13}$. The material appeared to be pure on thin-layer chromatograms in several solvents.

The high specificity of the enzyme for the diacyl-GPC is indicated by the fact that the ethanol-insoluble diacylglycerol phosphate fraction contained only trace amounts of alkenyl ether. Further evidence is the fact that prolonged treatment or retreatment of the alkenyl acyl-GPC with the cabbage phospholipase did not alter the product. We found that alkenyl acyl-GPE was difficult to prepare by this method 
using phospholipase $\mathrm{D}$ since it was hydrolyzed at an appreciable rate*, and the remaining unreacted material tended to be contaminated with diacyl-GPE. There is a possibility that the GPE and GPC derivatives may be attacked by different enzymes in the phospholipase $\mathrm{D}$ preparation with different specificities.

\section{DISCUSSION}

The results suggest that many of the enzymes catalyzing reactions of lipids may be more selective than was previously indicated. The replacement of an ester by an alkenyl ether which differs by only one oxygen atom appears to affect the reactivity at each of the three remaining sites in the phospholipid.

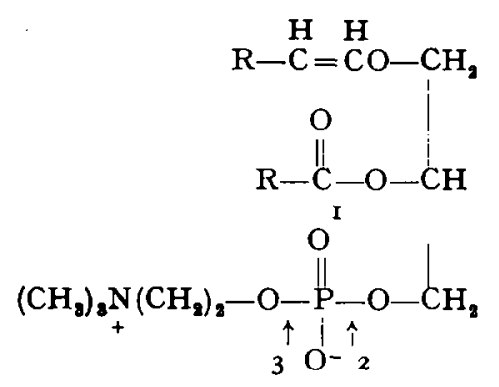

This inhibitory effect suggests that the metabolism of plasmalogens may not be as similar to that of diacyl phosphatides as the structures seem to indicate. Furthermore, a more careful study of the enzymes catalyzing reactions of phospholipids may show that much higher specificities exist than has generally been recognized.

The example of phospholipase $\mathrm{D}$ is particularly striking in that the bond to be hydrolyzed could be regarded as far removed ( 6 atoms) from the alkenyl ether. Work on the nonenzymatic synthesis of lecithin produced results that may be valuable in considering factors to help explain this "long-range" effect. Although GPC could not be satisfactorily acylated ${ }^{14,16}, \mathrm{Ba}^{2+}$ glycerol phosphorylethylchloride was readily acylated ${ }^{18}$, and BAER AND BUCHNEA ${ }^{17}$ later found that the $\mathrm{CdCl}_{2}$ complex of GPC can be successfully acylated. These results indicate that the effect of the phosphorylcholine on the glyceryl hydroxyls at carbon I and 2 can be modified but does not yet describe the mechanism of that effect. One feature common to all successful nonenzymatic acylation systems for phosphatides is the presence of a heavy metal ion that may form a complex with the phosphate group. At the present time no metal cofactors appear to be needed for the enzyme-catalyzed acylation of phosphatides ${ }^{11}$ when acyl-CoA esters are used as acylating agents.

The cis-alkenyl ether ${ }^{19}$ could be expected to have a more immediate steric effect on the reactivity at an adjacent carbon atom than the more linear acyl grouping. Thus, the limited reactivity at the 2-position with phospholipase $A$ and the lack of reactivity with the liver microsomal acyltransferase is understandable. An important consequence of the fact that alkenyl-GPC could not be acylated, however, is that in vivo the alkenyl group may be introduced after, rather than before, the 2-acyl substituent is present. This possibility is in keeping with the hypothesis that the diacyl 
derivative may be somehow converted directly to the alkenyl acyl derivative without any extensive rearrangement of the molecule. A further consequence would be that alkenyl-GPC may be only a catabolic (rather than anabolic) intermediate since the alkenyl-GPC, but not the alkenyl acyl-GPC, is attacked by the alkenyl ether hydrolase of rat liver ${ }^{19}$.

WARNER ${ }^{18,19}$ noted that phospholipase $\mathrm{C}$ (EC 3.1.4.3) is less active in catalyzing the hydrolysis of phosphorylcholine from alkenyl acyl-GPC than from diacyl-GPC. Starting with a lecithin preparation containing $44 \%$ alkenyl acyl-GPC, he obtained one of $74 \%$ alkenyl acyl-GPC after $5 \mathrm{I} \%$ hydrolysis. The unreacted material remaining after $89 \%$ of the initial sample was hydrolysed was essentially pure alkenyl acyl-GPC.

A variety of pure alkenylglycerol derivatives have been isolated by virtue of their stability in dilute alkali, in contrast to that of the acyl derivatives ${ }^{18,20}$. In addition, alkenyl acylglycerol is unusual in that it can be separated from its diacyl analog by silicic acid chromatography ${ }^{2,19}$. Apparently the absence of the highly polar phosphate substituents allows the physical differences in alkenyl ethers and esters to be manifested. Pure alkenyl acyl-GPC, however, was not isolated from diacyl-GPC in naturally-occurring mixtures until GOTTFRIED AND RAPPORT ${ }^{6}$ used venom phospholipase to catalyze hydrolysis of the diacyl-GPC at a faster rate than the alkenyl acyl-GPC. This mild and selective procedure allowed the isolation of alkenyl acylGPC in $32 \%$ yield. The cabbage enzyme, like the microsomal acyltransferases, seems to have an absolute specificity for only the acyl derivatives. Thus, cabbage phospholipase D now appears to be a better reagent for preparing alkenyl acyl-GPC since its selectivity is much higher than the venom phospholipase $\mathbf{A}$, and the product can be isolated in very high yields with less concern for stopping the reaction at a critical time.

\section{NOTE ADDED IN PROOF}

This effect was due to contamination of the hydrolysis products with peroxidized ethanolamine phosphoglycerides. Additional work in this laboratory by Sister P. M. SLAKEY showed that a clean separation of enzymatic products from the unreacted material was obtained when the starting material was purified with DEAFcellulose as described by RouSER et al. The results showed that diacyl-GPE was hydrolized much more rapidly than alkenyl acyl-GPE.

Received November rgth, rg64.

\section{ACKNOWLEDGEMENTS}

This work was supported in part by the National Institutes of Health (AM 053Io) and the National Science Foundation (GB-r75o). The authors thank Mr. J. A. Peterson for his help on the acyl-transferase studies.

\section{REFERENCES}

I G. Schmidt, L. Fingerman, W. A. Spencer and S. J. Thannhauser, Federation Proc, in (1959) 318.

2 J. Kiyasu and E. P. Kennedy, J. Biol. Chem., 235 (1960) 2590. 
3 E. F. Hartree and T. Mann, Biochem. J., 8o (I96I) 464.

4 G. V. Marinetit, J. Erbland and E. Stotz, Biochim. Biophys. Acta, 33 (1959) 403.

5 M. M. Rapport and R. E. Franzi, J. Biol. Chem., 225 (I957) 85 I.

6 E. L. GotTFried and M. M. Rapport, J. Biol. Chem., 237 (I962) 329.

7 W. E. M. Lands, Federation Proc., 20 (I96I) 280.

8 H. R. Warner and W. E. M. Lands, J. Biol. Chem., 236 (196r) 2404.

9 D. J. Hanahan, in M. J. Coon, Biochemical Preparations, Vol. 9, Wiley, New York, r962, p. 55. io H. R. Warner and W. E. M. Lands, J. Lipid Res., 4 (1963) 2 I6.

I I W. E. M. Lands, J. Biol. Chem., 235 (1960) 2233.

12 W. E. M. Lands AND P. HART, Federation Proc., 23 (1964).

I 3 G. B. Ansell and S. Spanner, J. Neurochem., io (I964) 945.

I 4 E. Baer and M. Kates, $J$. Am. Chem. Soc., 72 (1950) 942.

I 5 D. J. Hanahan, $J$. Biol. Chem., 207 (I954) 879.

i6 E. Baer, D. Buchnea and A. Newcombe, $J$. Am. Chem. Soc., 78 (1956) 232.

I E. Baer and D. Buchnea, Can. J. Biachem. Physiol., 37 (1959) 953.

i 8 H. R. Warner and W. E. M. Lands, $J$. Am. Chem. Soc., 85 (I963) 60.

I9 H. R. WARner, The Structure and Metabolism of Plasmalogen, Ph.D. Thesis, The University of Michigan, I962, University Microfilms, Ann Arbor.

20 E. F. Hartree and T. Mann, Biochem. J., 75 (1960) $25 \mathrm{I}$.

21 G. Rouser, G. Kritchevsky, D. Heller and E. Lieber, J. Am. Oil Chemist' Soc., 40 (I963) 425 .

Biochim. Biophys. Acta, 98 (1965) 532-538 